\title{
EXPLORING THE FACTORS INFLUENCING ENERGY EFFICIENCY IN THE GREEK HOTEL SECTOR
}

\author{
Christos Tourkolias* \\ Center for Renewable Energy Sources \\ 19th km Marathonos Ave, 19009, Pikermi Attiki Greece, ctourkolias@cres.gr \\ https://orcid.org/0000-0002-3835-8724
}

\author{
Areti Kontogianni \\ University of Western Macedonia, Kila Kozani, 50100 Kozani, Greece, akontogianni@uowm.gr \\ https://orcid.org/0000-0002-9183-6211 \\ Dimitris Damigos \\ National Technical University of Athens, 9, Iroon Polytechniou str, 15780 Zografou, Greece \\ damigos@metal.ntua.gr \\ https://orcid.org/0000-0003-0142-7156
}

Michalis Skourtos

Kuwait University, Jamal Abdul Nasser St, Kuwait, michail@cba.edu.kw

https://orcid.org/0000-0003-0597-3875

\begin{abstract}
The current paper aims at enhancing the existing literature of studies discussing the parameters, which formulate the phenomenon of the energy efficiency gap in hotels. Specifically, the obtained outcomes, as resulted by the conduction of a stated preference survey are presented and discussed. The survey was carried out on a representative sample of hotels in Greece in the context of the "Consumer Energy Efficiency Decision making (CONSEED)" project. Emphasis was given on various issues related to the energy efficiency gap, such as the impact of EU labelling scheme, the linkage of the pro-environmental behaviour with the willingness to invest in more energy-efficient technologies and equipment, the lack of information about electricity prices and the imperfect understanding of energy operating costs. The findings of the survey can be used to explain the role of the behaviour in the decision-making procedures for the further promotion of energy efficiency. Theoretical models can be developed with the collected data to examine the energy efficiency gap phenomenon and to quantify the contribution of different factors to its formulation including the calculation of the implicit discount rate. Finally, the design of more effective policies can be supported with the findings of the paper maximizing the private and social benefits, which are associated with the purchase of energy-efficient technologies and equipment in the hotel sector.
\end{abstract}

\section{Keywords}

energy labels; energy efficiency; energy behaviour; hotel industry; implicit discount rate

\section{Introduction}

In Greece, the role of tourism is vital for the whole economy. Specifically, the hotel sector contributed approximately $30.9 \%$ to the national GDP in 2018, while the number of employees in the hotel sector amounted to almost 1 million representing $25.9 \%$ of the total workforce [1]. The national revenues were equal to €15.6 billion resulted mainly from approximately 30 million tourists. Considering the current status of the infrastructure, more than 10 thousand hotels are available with a total capacity of 800 thousand beds.

The energy consumption of hotels is considerably high, affecting the competitiveness of the whole sector. According to Figure 1, the per unit primary energy consumption - calculated on the basis of the issued Energy Performance Certificates - of both rooms to let and hotels are higher than many other types of buildings in the tertiary sector. Moreover, the demand for the coverage of space cooling with specific comfort levels is crucial for the hotel sector in Greece, while the seasonality of the hotels creates an additional obstacle in the penetration

https://doi.org/10.32933/Actalnnovations.37.1• ISSN 2300-5599 • C 2020 RIC Pro-Akademia - CC BY 
of energy-efficient technologies, as their payback period is not considered as attractive enough for the hotel owners/managers.

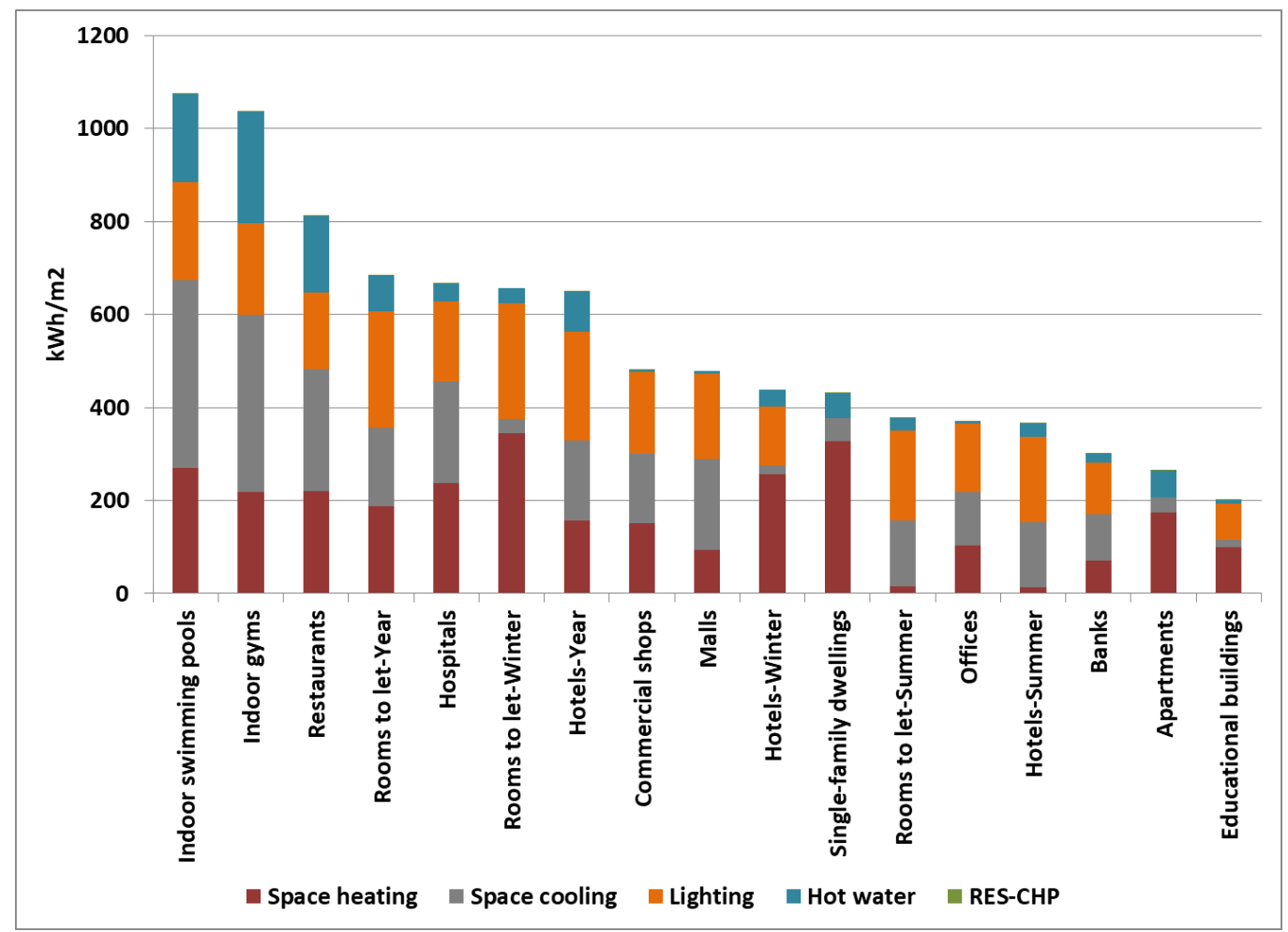

Fig. 1. Primary energy consumption of various types of buildings in the tertiary sector. Source: [2].

The final energy consumption of the hotels is affected by different types of parameters [3]. The physical parameters are related mainly with the characteristics of the building envelope, the climatic location conditions, the type of the installed equipment and technologies including the implemented operation and maintenance procedures and the utilised energy and water sources both in physical quantities and in cost. Furthermore, the operational parameters include: (i) the schedules for the operation of the different functionalities, (ii) the number of the provided facilities and services, (iii) the evolution of the occupancy, (iv) the perceived attitudes of the customers in relation with the indoor comfort levels, $(v)$ the implemented energy efficiency actions and (vi) the level of awareness and knowledge of both the personnel and customers in regards to the improvement of the energy efficiency.

Various scientific papers have analysed and assessed the relation of the hotels with the use and consumption of energy. Initially, the analysis and modelling of the energy consumption were prioritised including the identification of the parameters, which affect its evolution. For instance, Sheng et al. [4] developed both a model for analysing the energy use and specific energy benchmarks of five-star hotel sector in China. Idahosa et al. [5] conducted a panel analysis to understand the factors that drive the energy consumption of hotels in South Africa and Oluseyi et al. [6] explored the carbon footprint of hotels in Nigeria; Parpairi [7] presented the use of successful practises and policies in Greece. Cingoski \& Petrevska [8] discussed the obtained outcomes from an online survey among managers of different types hotels for evaluating the potential implementation of energy efficiency technologies in hotels and for identifying the factors, which affect the energy use and consumption. Also, several studies aimed at evaluating the energy and environmental performance of the hotels through the calculation of specific energy indicators [9-12] and the identification of the potential for the extensive penetration of the most effective energy efficiency technologies [13]. Also, emphasis has been put on the examination of customers' perceptions and behaviour towards the application of environmental practises by hotels [14-20]. Limited focus though has been placed on the behavioural aspects of the hotel owners/managers towards the promotion of energy efficiency. More specifically, Leroux and Pupion [21] examined the reasons for the adoption of the eco-label by the hoteliers. A non-parametric quantitative methodology was performed in 182 hotels in France in order to analyse the main factors leading to this choice. 
According to the obtained results, the adoption of the eco-label is affected by the risk perceptions, the adoption of eco-label and institutional issues. The regulatory and imitative behaviour and specific entrepreneurial characteristics, such as like risk-taking and bureaucracy, are considered as the main factors for the case of noncertified hotels, while the difficulties for obtaining the certification and the positive attitudes for the protection of the environment lead to the promotion of eco-labels in certified hotels. Asadi et al. [22] examined the potential effects of green innovation on sustainable performance in the hotel sector. Specifically, the factors influencing the adoption of green innovation were analysed resulting that the environmental and economic performances have the strongest influence for the promotion of green innovation in hotels. Finally, specific studies have examined the role of energy labelling on the formulation of the different perceptions and attitudes mainly for the residential appliances [23-25]. No study though was identified regarding the perceptions and attitudes of hotels owners/managers for the impact of energy labels in the equipment utilised in their premises. The limitations revealed by the literature review are critical because the majority of the countries have already set ambitious targets for increasing energy efficiency. Nevertheless, the "energy efficiency gap" or "energy paradox" [26] creates a serious problem as the businesses and the consumers in reality do not support the acceleration of the energy efficiency equipment or appliances even if the triggered benefits are much higher than the required costs (Damigos et al., 2020). According to Damigos et al. [23] various market and non-market failures contributed to the problem of the energy-efficiency gap, while the energy labels can be confronted by the intensive utilization of energy labels.

Aiming to contribute to knowledge and existing literature, this paper provides an insight into the factors, which are responsible for the energy efficiency gap in the hotel sector. Specifically, the results of a stated preference survey are presented as collected by approximately 100 Greek hotels owners/managers via the method of the computer-assisted web interviewing (CAWI) within the framework of the "Consumer Energy Efficiency Decision making (CONSEED)" project. The survey was designed to collect information about the factors affecting the decision for the purchase of energy-efficient heating and cooling systems. More specifically, the present research aims at:

- assessing the role of energy efficiency in the decisions, which are made by the hotel owners and managers compared with other operational attributes of the heating and cooling technologies ;

- $\quad$ studying specific market and behavioural barriers (such as the provision of incomplete and inadequate information, the imperfect understanding of the triggered energy operating costs and liquidity constraints) and hidden costs and benefits, which hinder the hotel owners and managers from potential investments in energy-efficient technologies and equipment;

- $\quad$ examining the role of various factors (socio-economic characteristics, attitudes, beliefs and perceptions) which affect the decision of the hotel owners/managers for further investments in the field of energy efficiency;

- $\quad$ evaluating the impact of the existing EU labelling scheme on energy-efficient investments and to test if the use of monetary labels would foster the willingness of hotel owners/managers to purchase more efficient heating and cooling systems;

- calculating the implicit discount rate used by the hotels owners/managers to compare the upfront costs of the energy-efficient technologies and equipment to the discounted value of future savings in energy expenditures during their decision to purchase an energy-efficient technology and equipment.

According to the authors' best knowledge, the above-mentioned issues have not been examined in the literature so far, and thus the current paper provides a solid basis for further discussions in the respective scientific questions. The structure of the paper consists of the Sections 2 and 3, which presents the utilised materials and methods and the obtained results correspondingly. Section 4 analyses the main outcomes of the conducted survey, while Section 5 summarises the main conclusions of the paper.

\section{Materials and methods}

\section{Survey design}

The survey was carried out among hotels owners/managers using a structured questionnaire. This approach allowed us to elicit specific information on particular variables and study the cause-effect relationships and connections as a function of the socio-economic and operational characteristics of the participated hotels into the survey $[27,28]$. The questionnaire was designed following the recommendations of the relative literature [29-33] to achieve the specific objectives of the research. After preparing the first version of the 
questionnaire, a pilot survey was conducted in order to test it and identify vague and problematic questions, which could lead to biased answers. The final version of the questionnaire comprised a set of specific, concise and standardised questions divided into seven parts. The first part aimed at examining the type of the installed heating and cooling technologies (either central systems or autonomous units), the intention of the participant to install a new heating and system (central or not) in period of five years and the degree of involvement of the participant in the process of purchasing the heating and cooling equipment. The second part investigated the role of the improvement of energy efficiency with other attributes of the heating and cooling technologies such as the price, the years of warranty, manufacturer's reliability, annual electricity consumption, after-sales service, the installed capacity of the heating and cooling technologies, the annual operating costs and the expected annual $\mathrm{CO}_{2}$ emissions. The discounting question was included in the third part of the questionnaire to elicit the expected return on the potential purchase of the energy-efficient heating and cooling system and to calculate the implicit discount rate. Specifically, the respondents considered the following question:

\begin{abstract}
"Suppose you could buy an energy-efficient cooling/heating system, which would reduce the operating costs of your hotel. The new cooling/heating system will cost $\{500,1000,1500\}$ more and is expected to operate for 10 years. How much would you have to save in your energy bill per year during the next 10 years to pay for the additional $\{500,1000,1500\}$ Euros?"
\end{abstract}

The fourth part of the questionnaire investigated attitudes and perceptions of the participants concerning the perceived costs and benefits emphasising the various barriers that hinder the further promotion of energyefficient technologies and equipment. The fifth part focused on the factors, which foster the utilisation of the current energy label and the proposed monetary label for the heating and cooling systems. Firstly, the hotel owners/managers declared their familiarity with the current energy label, while it was examined if selection and purchase of a new energy-efficient system has been mobilised by the energy label. Moreover, the participants evaluated if the energy label is understandable, reliable, used by sellers for the promotion of a specific type of technologies, affecting the decision for buying a specific unit and facilitating the potential buyer to realise her energy consumption and calculate the operating costs of the heating and cooling system. Participants were informed that the current energy label is planned to be substituted by an alternative, which provides information about the total energy cost on annual basis in addition to the annual energy consumption, as follows:
"Imagine the use of energy labels in heating and cooling systems is mandatory. These tags will provide the prospective buyer with information on the annual energy consumption of the heating and cooling systems in kWh and in addition the annual energy cost in euro. For example, "the annual energy cost of this device amounts to $€ Y$ annually". This information will be based on the model's cooling/heating power, its average energy efficiency and an average electricity price."

Then, they were asked to evaluate the various options assessed for the case of the existing energy label. The sixth part of the questionnaire explored the environmental perceptions of the participants and the potential installation of specific energy and environmental management systems including the renovation of the building envelope. Finally, the seventh part of the questionnaire information about the operational characteristics and the ownership of the hotel were collected.

The survey was carried out in December 2017 via the CAWI method by a specialised market research and opinion polling company in Greece. Specific quality assurance procedures were applied in compliance with the Data Collection Quality Control rules of the Association of Greek Market \& Opinion Research Companies. The target group was owners/managers of Greek hotels and 'rooms to let'. The sample derived by an online research panel maintained by the Opinion Research Company. Furthermore, the sample was selected to be representative in relation to the geographic dispersion and the main characteristics of hotels in Greece. Each hotel owner or manager was notified and received by email an electronic link to the survey questionnaire without the provision of any incentive to participate in the survey. Totally, 102 hotel owners/managers completed the developed questionnaire successfully.

\title{
Data analysis
}

The data were analyzed using univariate, bivariate and multivariate statistics. Univariate (i.e. descriptive) statistics was employed to summarize the variables relating to the perceptions, beliefs and characteristics of the 
participants. As far as the estimation of the implicit discount rate (IDR) is concerned, the Kaplan-Meier nonparametric estimator (Kaplan \& Meier 1958) was utilised to estimate the respective IDR value for those who answered the discounting question. With regards to the bivariate analysis, chi-square tests were conducted to examine potential associations between energy- and environmental-related perceptions and the demographic and attitudinal characteristics of the respondents. Finally, the data were also analysed using multivariate regression models (i.e. binary and ordered logistic ones) following the relevant literature [34-38], to explore which attitudinal and demographic factors influence energy-efficiency decision making.

\section{Results}

Description of the general characteristics of the hotels

According to the collected data, $42 \%$ of the hotel units operate as vocational hotels while $31 \%$ of them are located in cities covering different multi-purposes travels. Most of the examined hotels are privately owned (90\%); $46 \%$ of the hotels operate on continuous basis (12 months) and $35 \%$ of the hotels have seasonal operation (June to September). During high season, the occupancy rate exceeds $90 \%$ for the vast majority of the respondents ( $70 \%$ of the sample). The average hotel occupancy rate is equal to $57 \%$ while the average capacity amounts to 99.4 bed-places. The average hotel rating is equal to 2.55 stars while the average permanent and seasonal personnel is equal to 7.6 and 13.7 employees, correspondingly.

As regards the heating and cooling system, $25.5 \%$ of the hotels have in operation a central system, $63.7 \%$ a distributed system and the rest (i.e. 10.8\%) both systems. According to the obtained responses, the average energy cost is equal to $€ 4,412$ on monthly basis ( $\min : € 100$ max: $€ 90,000$ ), while is strongly related to the hotel rating and capacity. More specifically, the average monthly cost for the 1-star hotels is €860, for the 2-star hotels is $€ 3,100$, for the 3 -star hotels is $€ 1,700$, for the 4 -star hotels is $€ 5,400$ and for the 5 -star hotels is $€ 34,500$. Moreover, the average energy cost per month is $€ 140$ for 0 - 20 bed-places, $€ 2,100$ for 21 - 50 bed-places, $€ 3,800$ for 51-100 bed-places, $€ 4,600$ for $101-300$ bed places and $€ 90,000$ for more than 1,000 bed-places. In total, the average monthly energy costs per bed-place range from $€ 35$ to $€ 3,300$ (average: $€ 3,300 ;$ median: $€ 210$ ). Finally, the average energy cost is equal to $€ 2,700$ and to $€ 3,000$ on monthly basis for the case of hotels with central heating and cooling system and distributed system respectively. The operation of a mixed system leads to considerably highest energy cost (€16,300 per month).

According to Figure 2, 30\% of the participants stated that a Building Energy Management System has already been installed in their hotel. The percentage of the hotels, which have been, renovated amounts to $68 \%$ indicating the importance of energy efficiency in the operation of the hotel industry. The main reasons for the non-initiation of the required efficiency interventions are related to the relatively young age of the buildings and the difficulty to attain the appropriate funds for the energy upgrade of the buildings and the other facilities. Further, environmental interventions have been initiated. Explicitly, $41 \%$ of the sample has installed a waste reduction system, $44 \%$ a waste recycling system and $47 \%$ a water-saving system, demonstrating the emphasis given in addressing the environmental challenges triggered by the operation of the hotels. 


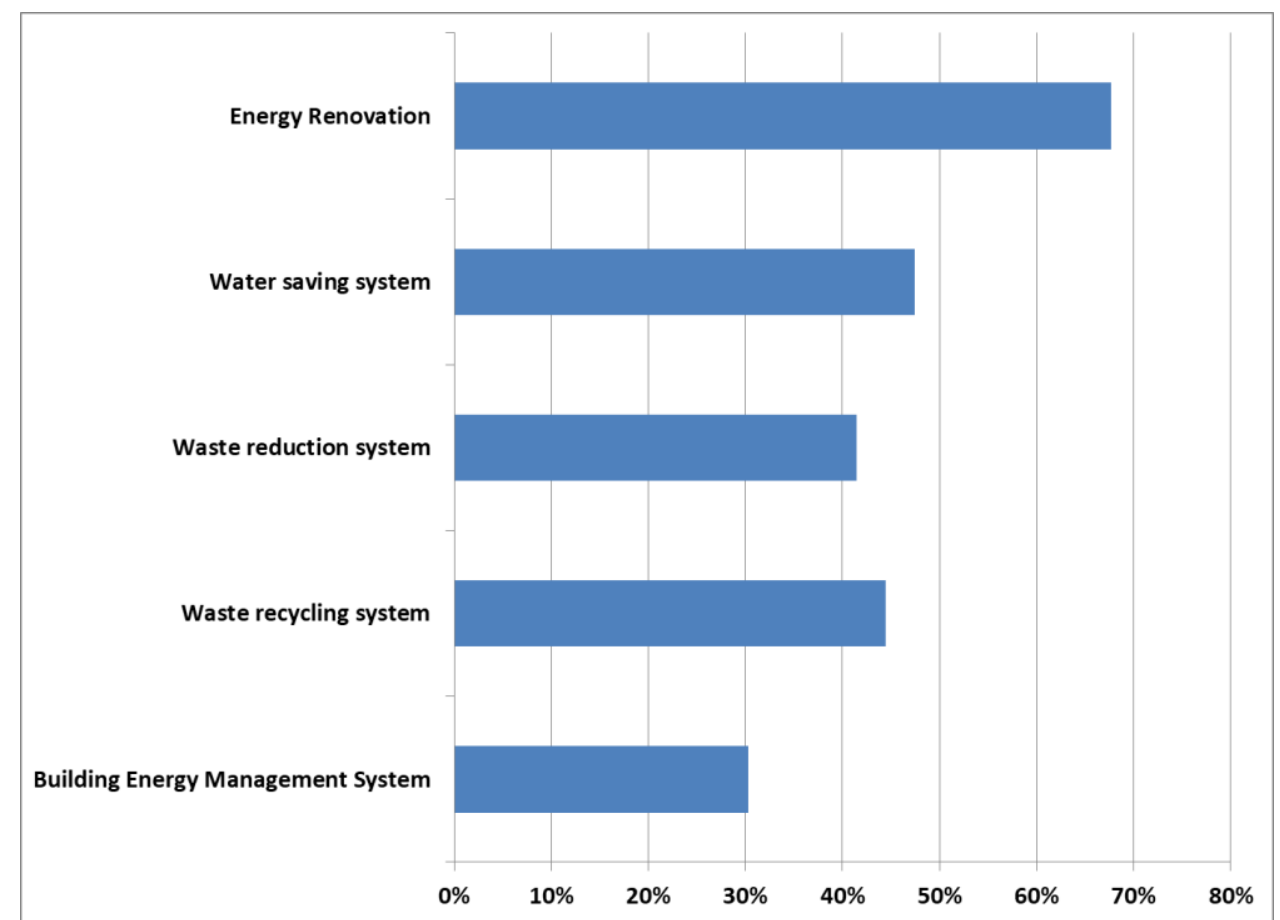

Fig. 2. Implemented energy and environmental interventions in the examined hotels

Factors affecting the purchase of heating and cooling systems

The factors that affect the purchase of heating and cooling systems were examined (Figure 3). The analysis showed that the energy consumption and the manufacturer's reliability $(89.2 \%)$ are considered as the most essential aspects from the hotel owners/managers during the purchase of the energy efficient heating and cooling systems. Moreover, the annual energy cost and the after-sales service are also considered important (81.4\%), followed by the capacity of the system, the years of warranty and the price $(79.4 \%, 78.4 \%$ and $74.5 \%$, respectively). The $\mathrm{CO}_{2}$ emissions are not considered as a crucial parameter for the selection of the heating/cooling system as only $66.7 \%$ of the respondents highlighted its importance. The factors that are linked with the performance of the heating and cooling systems and the comfort levels to ensure customers' satisfaction are considered as more important during the selection of a new heating and cooling system. Finally, $20 \%$ of the respondents plan to install a new heating and cooling system - either central or individual - within the next five years, while the majority of the participants $(57 \%)$ claimed that his involvement in the decision for selecting a new heating and cooling system is essential and definitive.

Chi-square tests revealed that women focus mainly on the manufacturer's reliability $($ chi2 $(1)=4.1839, p=0.041$ ) and the capacity of the system (chi2 $(1)=3.7503, p=0.053$ ). Furthermore, it seems that older people are more concerned about the price of the system ( $\operatorname{chi2}(3)=9.1127, p=0.028)$, the energy consumption (chi2(3) $=13.2082$, $p=0.004)$, the after sales service (chi2 $(3)=9.0016, p=0.029)$, the annual energy cost (chi2(3) $=18.5170, p=$ 0.000 ), and the $\mathrm{CO}_{2}$ emissions (chi2 $(6)=13.4253, \mathrm{p}=0.037$ ). Finally, in comparison to franchised hotels, privately owned hotels consider more important the years of guarantee (chi2 $(2)=12.6018, p=0.002)$, the manufacturer's reliability (chi2 $(1)=4.2549, p=0.039)$, the energy consumption (chi2 $(2)=11.4807, p=0.003)$, the capacity of the system (chi2(1) $=10.5332, \mathrm{p}=0.001)$, the annual energy costs (chi2(2) $=7.2091, \mathrm{p}=0.027)$, and the $\mathrm{CO}_{2}$ emissions (chi2 $(2)=12.1957, p=0.002)$. 


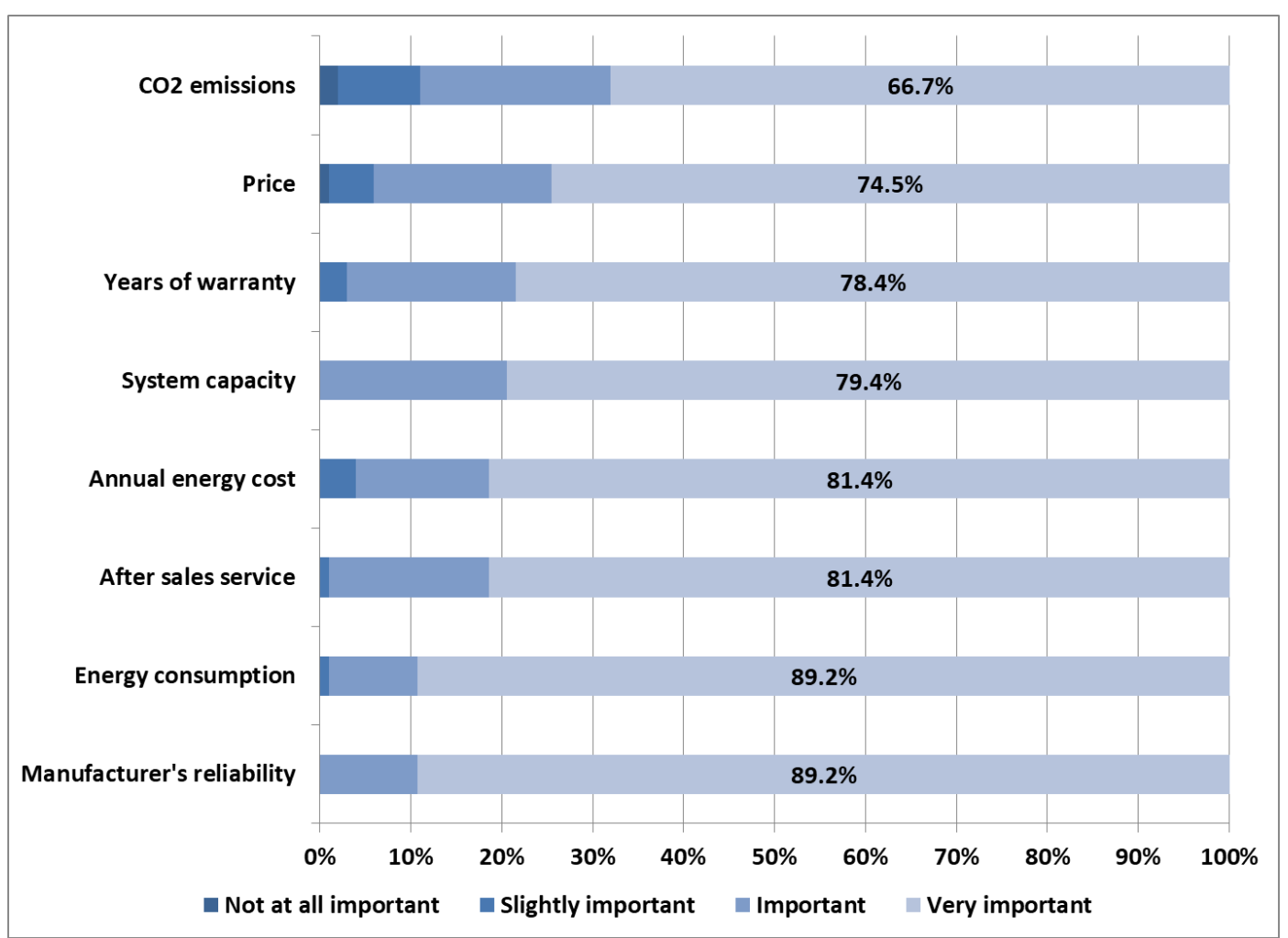

Fig. 3. Importance of factors affecting the purchase of heating and cooling systems at hotels.

\section{Perceptions towards energy efficiency and environment}

The analysis of the perceptions for the promotion of energy efficiency in hotels (Figure 4) demonstrates that the vast majority of the participants link strongly the energy efficiency technologies with the reduction of the energy consumption and the triggered environmental impacts (93.1\% and $91.2 \%$ of the sample, respectively). Furthermore, more than $80 \%$ of the responders stated that the energy upgrade of the heating and cooling equipment would be proved beneficial to them as they will improve the existing comfort levels and will lead to an increase of the current value of the enterprise ( $84.3 \%$ and $82.4 \%$ of the sample, respectively).

The majority of the participants initially said that have adequate knowledge of the issues about energy use and consumption and the energy prices. Specifically, the hotel owners/managers claimed that they are informed about the energy prices ( $83.3 \%$ of the sample), understand the heating and cooling system's energy consumption ( $81.4 \%$ of the sample) and are certain about the economic benefit triggered by the more energy-efficient system ( $77.5 \%$ of the sample). Nevertheless, approximately $90 \%$ of the participants admitted that they are not informed of the existing energy consumption of the hotel, and about $47 \%$ of the respondents were neither able nor willing to mention the required energy costs for the operation of their hotels.

The obstacle of the limited financial incentives was also highlighted as $53.9 \%$ of the participants claimed that it is not possible to finance the upgrade to a more energy-efficient cooling/heating system, while the limited financial incentives was mentioned by $66.7 \%$ of the sample as the most important barrier towards making more energy-efficient choices.

Furthermore, a problem was pinpointed regarding the identification of the energy-efficient heating and cooling systems. Specifically, $39.2 \%$ the sample are not capable of recognizing the energy-efficiency heating and cooling systems demonstrating the need to provide more accurate information, while $28.4 \%$ support the statement that all the new heating and cooling technologies have identical energy performance levels. Yet, the majority of the participants seem to trust the technical reliability of the energy-efficient heating and cooling systems; less than $10 \%$ strongly believe that more energy-efficient heating and cooling systems are less reliable. Finally, the vast majority of the participants expressed their concern about the main problems of the environment such as pollution, climate change etc. Specifically, $76 \%$ and $20 \%$ of the sample are very worried and worried correspondingly about the current status of the environment; only $4 \%$ downgrades the severity of the environmental problems. 
More energy efficient systems are less reliable

I would be more likely to buy an energy efficient system if my peers do so

All new systems have similar energy efficiency levels

I don't know which systems are enegry efficient

I cannot afford to buy an energy efficient system

Lack of financial incentives prevents me from making more energy efficient choices

I understand how much money I would save if I bought a more energy efficient system

I have a good understanding of my system's energy consumption

Upgrading my heating/cooloing system would increase the value of my unit

I am aware of electricity energy prices

Upgrading ny heating/cooling system would improve the comfort of my unit

Buying a more energy efficient system would reduce my unit's environmental impact

I am willing to take a chance on new technologies to reduce my energy consumption

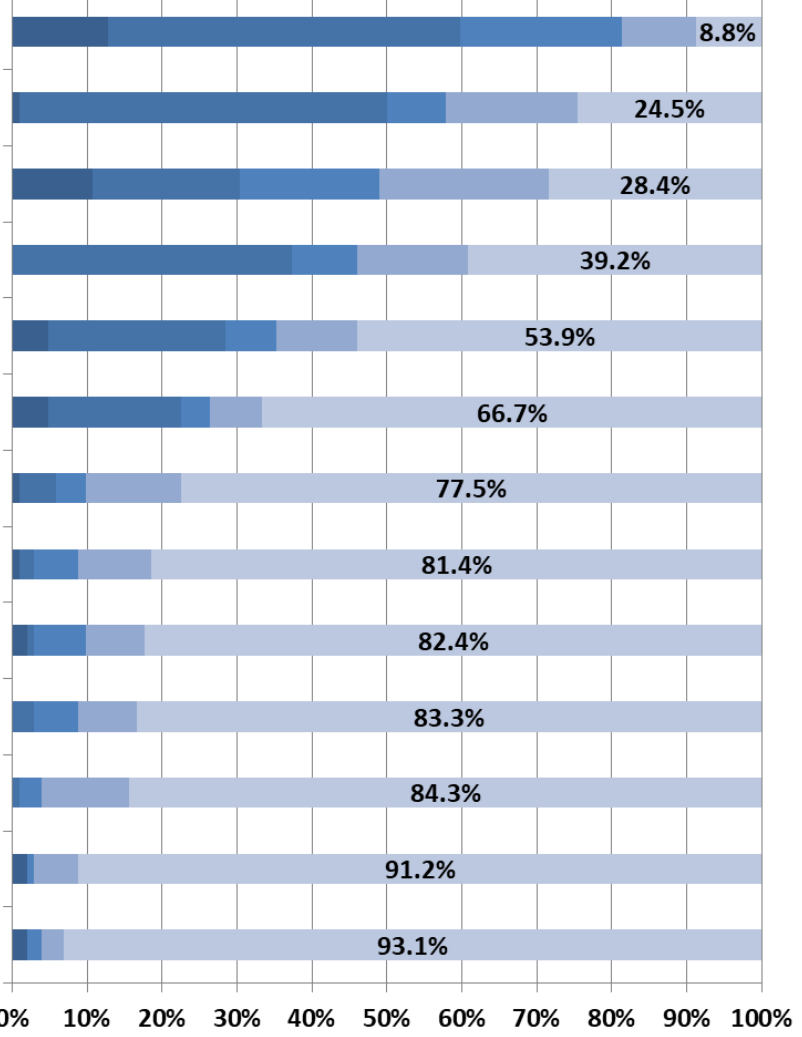

Don't know/No response $\quad$ Strongly disagree

- Slightly disagree $\quad$ Slightly agree $\quad$ Strongly agree

Fig. 4. Agreement with specific statements about energy efficient heating and cooling systems at hotels.

Chi-square tests lead to the conclusion that women face more significant barriers due to the limited financial incentives, which are available (chi2 $(2)=16.0959, p=0.000)$. Older people support the exploitation of new technologies to reduce their energy consumption (chi2 $(6)=14.0135, p=0.029$ ), face more significant barriers due to the lack of the financial incentives $(\operatorname{chi} 2(6)=22.5244, p=0.001)$, and are more willing to buy and install a more energy-efficient cooling/heating system if their peers do so $($ chi2 $(6)=15.4456, p=0.017)$. Finally, private owners face more significant barriers due to the lack of the financial incentives (chi2 $(2)=9.2056, p=0.010)$, and are less likely to buy and install a more energy-efficient cooling/heating system if their peers do so (chi2(2) $=11.1793, \mathrm{p}=0.004)$.

Understanding, opinions and beliefs about the different version of the energy labels

About two-thirds of the respondents have been informed about the current energy labels, while approximately $70 \%$ claimed that the energy labels affected their decision to buy the already installed heating and cooling system. Further, a comparison was initiated between the current energy label and the alternatively proposed based on the provided monetary information. According to Figure 5, the participants confirmed that the current energy labels are understandable (74\%), trustworthy (54\%), can affect the consumer's decision (79\%) and facilitates the better understanding of system's energy consumption and the easiest calculation of the operating costs (70\%). Moreover, they claimed that the current energy labels are manipulated and utilised by the sellers $(66 \%)$ so as to foster the decisions of the potential consumers. The proposed monetary labels manage to improve the understanding (86\%) and the trustworthiness (56\%) compared to the current energy labels. Furthermore, the realization of the system's energy consumption and the calculation of the operating costs are performed more effectively according to the statement of $90 \%$ of the respondents. Nevertheless, the proposed monetary label seems to influence negatively the purchase decision ( $74 \%$ of the sample strongly agree) since the sellers will use it as a more effective tool for manipulating potential consumers ( $77 \%$ of the sample strongly agree). It should be noted that no statistical significance was resulted by the analysis of the differences between the two examined types of labels. 


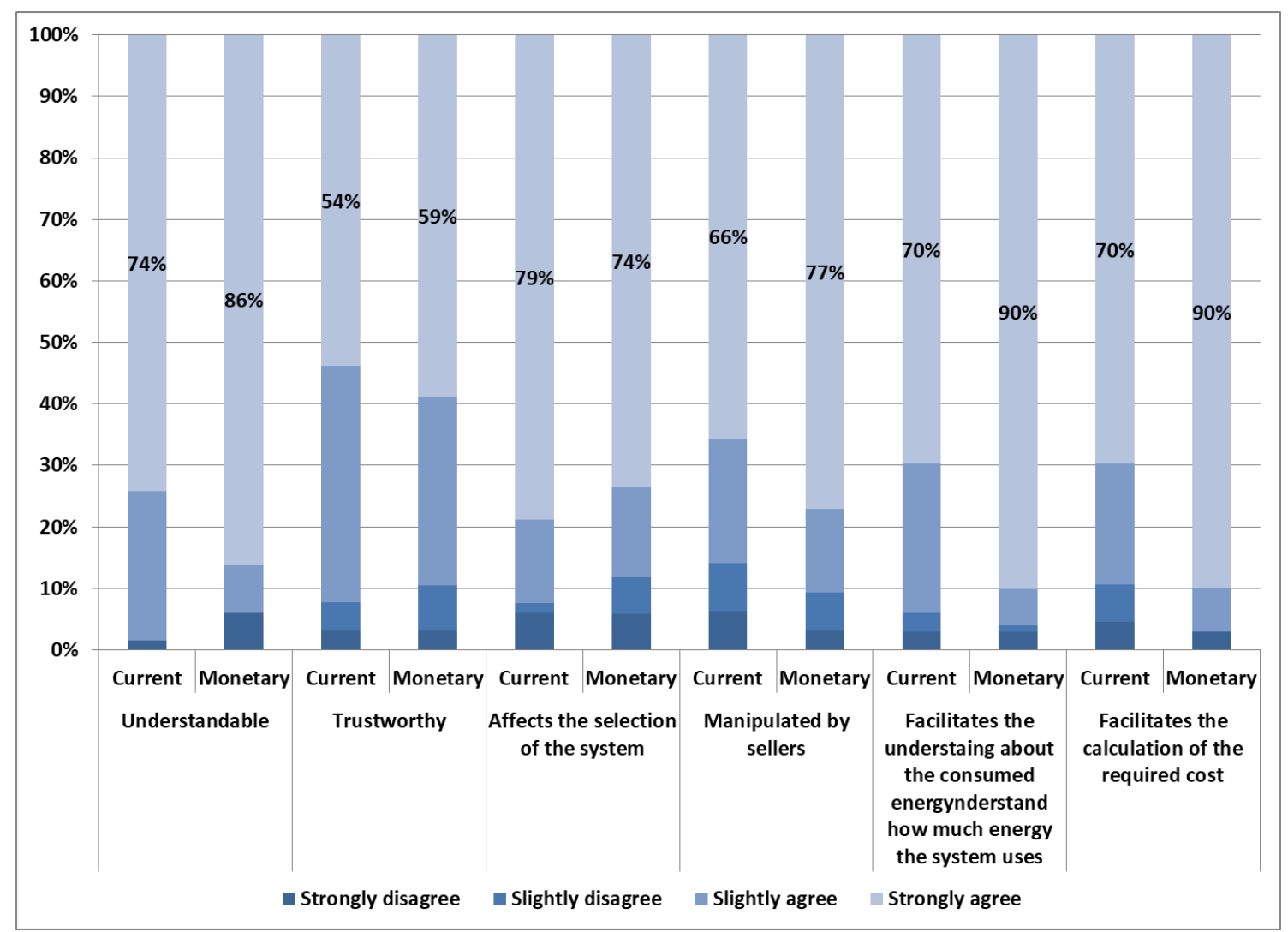

Fig. 5. Comparison of the alternative version of the energy labels.

\section{Exploring the factors affecting the valuation of energy efficiency}

\section{A. Importance of energy consumption in choosing energy-efficient heating and cooling systems}

The exploration of the factors, which constitutes energy consumption as the main determinant during the selection of energy-efficient heating and cooling systems in hotel sector was implemented through an ordered logistic model (dependent variable coded as $1=$ Not at all important, $2=$ Not very important; $3=$ Fairly important and 4 = Very important). The obtained outcomes in Table 1 revealed that the energy efficiency is considered as more important for those who believe that the role of the installed capacity of the heating and cooling systems (coefficient $=3.163$ ) and the annual operating cost of the enterprise (coefficient $=1.791$ ) is the most important and are willing to use new technologies for reducing the operating costs (coefficient $=2.779$ ). Furthermore, the importance of energy efficiency varies by the hotel rating (coefficient $=-0.810$ ). The odds of mentioning the energy consumption as more important are 23.6 times greater for those who perceive as crucial the role of the installed capacity of the selected heating and cooling systems under the prerequisite that all of the other variables in the model are retained constant. Similarly, the importance is higher for those who also consider important the annual operating cost of the enterprise (6.0 times) and for those who intended to use new technologies for reducing the operating costs (16.1 times). Finally, the importance of energy efficiency decreases by almost $45 \%$ as the hotel rating increases. 
Table 1. Factors of the role of energy consumption during the selection of energy-efficient heating and cooling systems

\begin{tabular}{|c|c|c|}
\hline Variables (Coding in parentheses) & Coefficient & Standard error \\
\hline $\begin{array}{l}\text { Importance of the installed capacity of the heating and cooling systems } \\
(1=\text { Not at all important to } 4=\text { Very important })\end{array}$ & $3.163^{* *}$ & 1.461 \\
\hline $\begin{array}{l}\text { Importance of the annual operating cost } \\
\text { ( } 1=\text { Not at all important to } 4=\text { Very important })\end{array}$ & $1.791^{* * *}$ & 0.698 \\
\hline $\begin{array}{l}\text { Willingness to use new technologies for reducing the operating costs } \\
\text { ( } 1 \text { = Fully disagree to } 4=\text { Fully agree) }\end{array}$ & $2.779^{* *}$ & 1.180 \\
\hline $\begin{array}{l}\text { Hotel rating } \\
(1=\text { one star to } 4=5 \text { stars })\end{array}$ & $-0.810^{* *}$ & 0.395 \\
\hline Constant cut1 & 20.103 & 10.250 \\
\hline Constant cut2 & 23.443 & 10.866 \\
\hline Observations = 100; Log likelihood $=-37.74 ;$ Pseudo $R^{2}=0.496$ & & \\
\hline
\end{tabular}

\section{B. Awareness of the existing heating and cooling systems energy label}

The examination of the factors, which affects the awareness of the existing energy labels of the various heating and cooling systems (dependent variable coded as $1=$ Yes; $0=$ No) was carried out by a binary logistic model. According to the obtained results (Table 2), those who don't state that 'it is likely to purchase an energy-efficiency heating and cooling system in the case that other enterprises proceed with the same decision' (coefficient = 0.524), identify the energy-efficient heating and cooling systems (coefficient $=-0.592$ ) and have already installed a water conservation system (coefficient $=1.315$ ) are more probable to be aware of the existing energy label for the heating and cooling systems. The odds of being informed about the energy label are 3.7 times greater for those who have decided to install a water conservation system under the prerequisite that all of the other variables in the model are retained constant. Finally, the odds are $10 \%$ lower for those who disagree with the statement 'it is likely to purchase an energy-efficiency heating and cooling system in the case that other enterprises proceed with the same decision' and who identify the energy-efficient heating and cooling systems.

Table 2. Determinants of energy label awareness

\begin{tabular}{|l|c|c|}
\hline Variables (Coding) & Coefficient & Standard error \\
\hline $\begin{array}{l}\text { It is likely to purchase an energy-efficiency heating and cooling system in the } \\
\text { case that other enterprises proceed with the same decision } \\
(1=\text { Fully disagree to 4 = Fully agree) }\end{array}$ & $-0.524^{* * *}$ & 0.202 \\
\hline $\begin{array}{l}\text { It is not feasible to identify the energy-efficient heating and cooling systems } \\
(1=\text { Fully disagree to 4 = Fully agree) }\end{array}$ & $-0.592^{* * *}$ & 0.530 \\
\hline $\begin{array}{l}\text { A water conservation system has been installed in the enterprise } \\
(1=\text { Yes and 0 = No) }\end{array}$ & $1.315^{* *}$ & 0.207 \\
\hline Constant & $3.034^{*}$ & 0.806 \\
\hline Observations $=99 ;$ Log likelihood $=-46.8 ;$ Pseudo $\mathrm{R}^{2}=0.248$ & & \\
\hline \multicolumn{1}{|l}{$(* * * p<0.01, * * p<0.05, * p<0.1)$} & & \\
\hline
\end{tabular}

\section{Influence of the existing energy label in choosing heating and cooling systems}

The role of the energy labels into the formulation of consumers' decision (dependent variable coded as $1=$ Yes; $0=\mathrm{No}$ ), was examined through a binary logistic model (Table 3). According to the obtained results, those support the statement that all the new heating and cooling systems have similar levels of energy efficiency (coefficient = -0.734), believe that the lack of financial incentives hinders the investments in energy efficiency (coefficient = 0.595), are willing to invest in energy efficiency under the precondition that other enterprises proceed with the same decision (coefficient $=-0.427$ ) and their enterprise does not have a Building Energy Management System (coefficient $=0.991$ ), are less probable to be affected by the energy label when selecting a heating and cooling systems. Specifically, those who state that all the new heating and cooling systems have similar levels of energy performance, who face financial constraints and are affected by their peers, are less probable to be affected by the energy label by almost $48 \%, 55 \%$ and $65 \%$, respectively. On the other hand, those who have and operate a Building Energy Management System are 2.7 times more probable to take into consideration the energy labels 
when buying heating and cooling systems for their enterprises.

Table 3. Determinants of the energy label's role in choosing heating and cooling systems

\begin{tabular}{|c|c|c|}
\hline Variables (Coding) & Coefficient & Standard error \\
\hline $\begin{array}{l}\text { All new heating and cooling systems have similar levels of energy efficiency } \\
\text { ( } 1 \text { = Fully disagree to } 4 \text { = Fully agree) }\end{array}$ & $-0.734^{* * *}$ & 0.264 \\
\hline $\begin{array}{l}\text { Lack of financial incentives is a barrier for making more energy-efficient } \\
\text { choices } \\
\text { ( } 1=\text { Fully disagree to } 4 \text { = Fully agree) }\end{array}$ & $-0.595^{* *}$ & 0.306 \\
\hline $\begin{array}{l}\text { It is likely to purchase an energy-efficiency heating and cooling system in the } \\
\text { case that other enterprises proceed with the same decision } \\
\text { ( } 1 \text { = Fully disagree to } 4 \text { = Fully agree) }\end{array}$ & $-0.427^{* *}$ & 0.218 \\
\hline $\begin{array}{l}\text { Existence of Building Energy Management System } \\
(1=\text { yes and } 0=\text { no })\end{array}$ & $0.991^{* * *}$ & 0.636 \\
\hline Constant & 5.713 & 1.512 \\
\hline Observations = 83; Log likelihood = - 21.6; Pseudo $\mathrm{R}^{2}=0.212$ & & \\
\hline
\end{tabular}

\section{Calculation of implicit discount rates}

The implicit discount rate (IDR) is estimated using the following equation as the internal rate of return (IRR) of the investment on the energy-efficient cooling and heating system:

$$
C_{0}=\sum_{t=1}^{10} \frac{A E S_{t}}{(1+I D R)^{t}}
$$

where $C_{0}$ is the investment of 500, 1000 or 1500 Euros and $A E S_{t}$ is the annual energy savings requested by the respondent

In total, only $39 \%$ of the participants responded to the IDR questions. The vast majority (i.e. more than $90 \%$ ) of those who didn't answer the question said that they didn't know how to estimate future savings. Those who stated an amount for the required annual savings were asked the reason why they declared the specific amount. Practically all respondents justified their answer by calling on the payback period of the investment (i.e. "I want to get my money back in .... years"). This finding is an indication that respondents may lack the knowledge required to do the financial calculations required and, thus, rely on simple rules of thumb, as other scholars have also noticed [39-41]. For this reason, the payback period was also estimated, besides the IRR, based on the responses provided by the participants.

The minimum IDR was equal to $0 \%$ and the maximum $480 \%$, respectively. The non-parametric Kaplan-Meir statistics (i.e. mean and median values and the respective 95\% confidence intervals) are presented in Table 4. The minimum payback period is less than 3 months and the maximum is 10 years. The non-parametric mean and median values, together with the lower and upper $95 \%$ bounds were also estimated using the Kaplan-Meier estimator and the results are given in Table 5. Figure 6 illustrates the 'survival' curves for the IDR and the payback period, accordingly. 
Table 4. Kaplan-Meir estimates for the IDR (\%)

\begin{tabular}{|c|c|c|c|c|c|c|c|}
\hline \multicolumn{4}{|c|}{ Mean } & \multicolumn{4}{|c|}{ Median } \\
\hline Estimate & Std. Error & $\begin{array}{r}95 \% \text { C } \\
\text { Lower B }\end{array}$ & $\begin{array}{l}\text { nterval } \\
\text { er Bound }\end{array}$ & Estimate & Std. Error & $\begin{array}{r}95 \% \text { Con } \\
\text { Lower Bou }\end{array}$ & $\begin{array}{l}\text { nterval } \\
\text { er Bound }\end{array}$ \\
\hline $65.5 \%$ & $15.8 \%$ & $34.5 \%$ & $96.5 \%$ & $31.1 \%$ & $1.2 \%$ & $28.7 \%$ & $33.5 \%$ \\
\hline
\end{tabular}

Table 5. Kaplan-Meir estimates for the payback period (years)

\begin{tabular}{|c|c|c|c|c|c|c|c|}
\hline \multicolumn{4}{|c|}{ Mean } & \multicolumn{4}{|c|}{ Median } \\
\hline Estimate & Std. Error & $\begin{array}{r}95 \% \\
\text { Lower }\end{array}$ & $\begin{array}{l}\text { terval } \\
\text { r Bound }\end{array}$ & Estimate & Std. Error & $\begin{array}{r}95 \% \mathrm{Cc} \\
\text { Lower Bc }\end{array}$ & $\begin{array}{l}\text { terval } \\
\text { Bound }\end{array}$ \\
\hline 3.5 & 0.45 & 2.6 & 4.3 & 3.0 & 0.2 & 2.7 & 3.4 \\
\hline
\end{tabular}
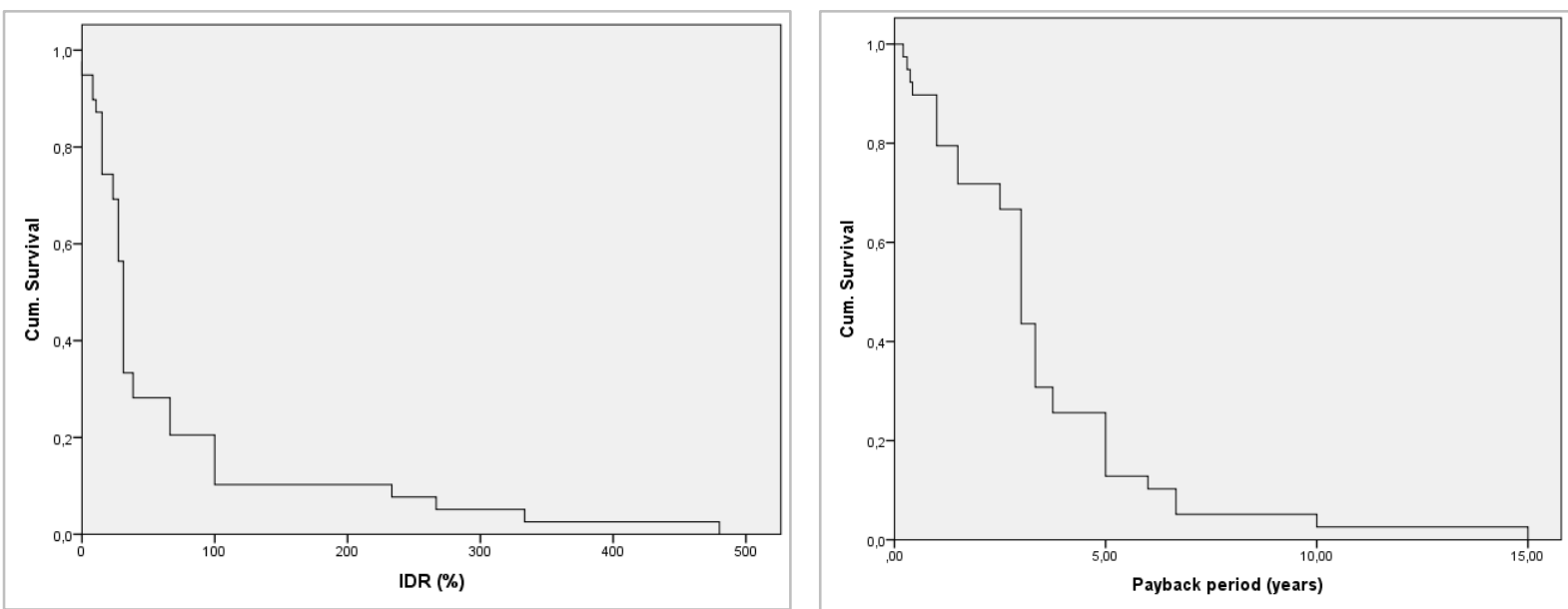

Fig. 6. IDR (left) and payback period (right) 'survival' curves

Finally, the factors affecting the IDR of the hotel owners/managers were explored through a log-linear regression model. According to the results, the value of the IDR increases for the women (coefficient $=0.730$ ) and for those who are not risk adverse, in general (coefficient $=0.103$ ) and decreases with the increase in the capacity of the hotel (coefficient $=-0.150$ ). According to the coefficients, and given the log-linear form of the model, the IDR for the women is more than twice as high as that for men. Further, a one-unit increase in riskiness increases the IDR by almost $11 \%$, while a one-unit change in the capacity of the hotel changes the IDR by $14 \%$.

Table 6. Determinants of the IDR of the hotel owners/managers

\begin{tabular}{|l|c|c|}
\hline Variables (Coding) & Coefficient & Standard error \\
\hline $\begin{array}{l}\text { Gender } \\
(1=\text { Male and 2 = Female) }\end{array}$ & $0.730^{* *}$ & 0.316 \\
\hline $\begin{array}{l}\text { Willingness to take risk } \\
(1=\text { not at all; } 10=\text { totally willing) }\end{array}$ & $0.103^{* *}$ & 0.061 \\
\hline $\begin{array}{l}\text { Capacity of the hotel in beds } \\
(1=1-20,2=21-50,3=51-100,4=101-150,5=151-200,6=201-300,7=301-500, \\
8=501-1000,9>1000)\end{array}$ & $-0.150^{* *}$ & 0.069 \\
\hline Constant & $2.440^{* * *}$ & 0.591 \\
\hline Observations = 35; Adj. R-squared $=0.206$ & & \\
\hline
\end{tabular}

Note: The dependent variable is the $\ln (I D R) ; * * p<0.01, * * p<0.05, * p<0.1$ 


\section{Impacts}

Worldwide, governments adopt policies to improve energy efficiency in end-use sectors. However, energyefficient technologies are not usually adopted despite the fact that it is strictly required for businesses in accordance with the private costs and the delivered benefits. The "under-investment" in energy-efficient technologies, is known as "energy efficiency gap" or "energy paradox" [42] and has been high on the priority list for at least three decades. Previous research suggests that energy paradox is relate among others to the market and non-market failures, biased beliefs, bounded rationality and heuristic decision-making [43].

The main objective of the current paper is the enhancement of the energy policy and research agendas by exploring the factors affecting energy efficiency decisions in the hotel industry. To this end, the paper illustrates the results of a stated preference survey conducted in a sample of Greek owners/managers of collective accommodation facilities. To the authors' best knowledge, this is the first attempt to gather and analyse information on the main factors, which are associated with the energy efficiency gap in the Greek hotel sector. More explicitly, the survey explored issues such as the effectiveness of energy labels and the role of proenvironmental behaviour on the decision-making procedures applied by the hoteliers, the impact of misinformation about the energy consumption and cost on the energy efficiency gap, the significance of the energy-efficiency with other attributes of heating and cooling equipment, etc.

The concluded outcomes by the survey indicate that the hotel industry is not inattentive to energy efficiency. The energy consumption, together with the reliability of the manufacturer, dominates the purchase decision of a heating/cooling system. These factors are linked with the effort of the industry to ensure customers' satisfaction. The majority of the respondents seem to be sufficiently informed about the energy labels (approximately $70 \%$ of the sample). It should be highlighted that the vast majority of the participants link the energy efficiency technologies and equipment with the reduction of the energy consumption and the related environmental impacts, suggesting the importance of pro-environmental behaviour in the transition towards more sustainable tourism industry. Moreover, the survey revealed several important types of barriers and biases (both market and behavioural). For instance, more than half of the respondents argue that they are not able to pay for the installation of energy efficiency technologies and nearly two-thirds indicated the limited financial incentives, which are available, as the most important barrier hindering their energy-efficient decisions. Further, there is evidence of bounded rationality provided that the majority of the respondents said is not been informed about the actual their energy consumption of the hotel, $60 \%$ didn't reply to the discounting question claiming that the cannot estimate future energy savings, half of them was not able or willing to state their actual energy costs and almost $40 \%$ admitted that they are not capable of recognizing the energy-efficiency heating and cooling systems. Finally, the estimated mean IDR is high (i.e. 65.5\%), although it lies within the range reported by other empirical studies [44]. The high IDRs and, consequently, the very short payback periods are not uncommon in corporate decision-making and are related to “...irrational 'safety margin' without any further economic rationale..." [44]. Yet, this could hinder the adoption of energy-efficient technologies, since, in real investments, such requirements are rarely satisfied.

The above-mentioned remarks could provide the evidence base for policy-development for the improvement of the energy efficiency in the hotel industry and bring significant environmental and socio-economic benefits. According to previous studies, the energy saving potential in hotels ranges from $10 \%$ to $25 \%$ of the energy they consume depending on the geographic region and other parameters [7]. The same conclusion is confirmed by several European studies, which presents estimated savings of $15-20 \%$ for heating, $40-70 \%$ for produced hot water, $7-60 \%$ for lighting and 5-30\% for cooling [3]. Reducing the energy consumption would result in economic benefits given that energy costs typically account for 3-6\% of overall operational costs of hotels [45]. For instance, on average hotels, a comprehensive energy management plan could reduce total energy demand by $742 \mathrm{MWh}$ per year [46]. Additional economic benefits could result from tourists who place importance on hotels implementing green practices $[14,15]$. Environmental benefits would result from the reduction of $\mathrm{CO}_{2}$ and air pollutants associated with energy generation. For instance, the standard emission factor for electricity consumption, in EU-27, is 0.460 t CO2 per MWhe [47]. Finally, improving energy efficiency in hotels may have social benefits. The economic robustness of the sector could be strengthened and, thus, the employment could be maintained or even further increased. 


\section{Conclusions}

This main objective of the study was the enhancement of the existing literature in regards to the energy efficiency gap in the hotel sector. The outcomes of the survey provide some new insights for policy purposes. For instance, policy-makers should support the development and evaluation of new promising policies, which could alleviate barriers and biases, e.g. the lack of financial support, the lack of access to loans, the limited realization of the energy use and consumption and the energy prices, the reduction of the 'discounting gap', i.e. the difference between market rates and implicit discount rates, etc. Further, they should 'nudge' the hoteliers in the direction of energy efficiency by promoting the environmental, social and economic benefits for their businesses (e.g. the increasing demand for green hotel accommodation worldwide). Yet, any policy recommendations should be treated taking into consideration the relatively small sample size and the fact that the reliability of the received answers depends on participants' capability to provide the appropriate responses. Finally, the outcomes and the limitations of the survey may serve as starting points for future research, especially as regards the role of behavioural biases and the factors affecting the 'discounting gap' and the energy-related financial illiteracy of the hoteliers. To this direction, future surveys should employ larger sample sizes and more complex designs (e.g. split-sample techniques, choice experiments, etc.) for exploring the hoteliers' energy-related investment behaviour and its interrelationship with the energy paradox.

\section{Conflict of interest}

The authors declare that they have no conflict of interest.

\section{Acknowledgements}

This work was supported by the CONSEED Project (CONsumer Energy Efficiency Decision making) funded under the HORIZON Framework Programme of the European Commission (Contract No. 723741).

\section{References}

[1] Greek Tourism Confederation. Greek Tourism - Basic Figures 2018 2020. https://sete.gr/en/strategy-fortourism/basic-figures-repository/.

[2] Greek Ministry of Environment and Energy. Registry of the statistical results for the energy performance of the buildings 2020. http://www.ypeka.gr.

[3] Hotel Energy Solutions. Analysis on Energy Use by European Hotels - Online Survey and Desk Research. 2011.

[4] Sheng Y, Miao Z, Zhang J, Lin X, Ma H. Energy consumption model and energy benchmarks of five-star hotels in China. Energy and Buildings, 165 (2018), 286-292.

[5] Idahosa LO, Marwa NN, Akotey JO. Energy (electricity) consumption in South African hotels: A panel data analysis. Energy and Buildings, 156 (2017), 207-217.

[6] Oluseyi PO, Babatunde OM, Babatunde OA. Assessment of energy consumption and carbon footprint from the hotel sector within Lagos, Nigeria. Energy and Buildings, 118 (2016), 106-113.

[7] Parpairi K. Sustainability and Energy Use in Small Scale Greek Hotels: Energy Saving Strategiesand Environmental Policies. P Procedia Environmental Sciences, 38 (2017), 169-177.

[8] Cingoski V, Petrevska B. Making hotels more energy efficient: The managerial perception. Economic Research-Ekonomska Istraživanja, 31 (2018), 87-101.

[9] Karagiorgas M, Tsoutsos T, Moiá-Pol A. A simulation of the energy consumption monitoring in Mediterranean hotels. Application in Greece. Energy and Buildings, 39 (2007), 416-426.

[10] Lu S, Wei S, Zhang K, Kong X, Wu W. Investigation and analysis on the energy consumption of starred hotel buildings in Hainan Province, the tropical region of China. E Energy Conversion and Management, 75 (2013), 570 580.

[11] Pieri SP, Tzouvadakis I, Santamouris M. Identifying energy consumption patterns in the Attica hotel sector using cluster analysis techniques with the aim of reducing hotels' CO2 footprint. Energy and Buildings, 94 (2015), 252-262.

[12] Eva M, Yacob M, Walter W. Energy consumption in the Greek hotel sector: The influence of various factors on hotels' carbon footprints under the implementation of the EU and Greek legislative framework. In: Howlett R.J., Jain L.C., Lee S.H. (eds) Sustainability in Energy and Buildings, 2009. Springer, Berlin, Heidelberg.

[13] Bianco V, Righi D, Scarpa F, Tagliafico LA. Modeling energy consumption and efficiency measures in the Italian hotel sector. Energy and Buildings, 149 (2017), 329-338.

[14] Kang KH, Stein L, Heo CY, Lee S. Consumers' willingness to pay for green initiatives of the hotel industry. International Journal of Hospitality Management, 31 (2012), 564-572. 
[15] Kostakis I, Sardianou E. Which factors affect the willingness of tourists to pay for renewable energy? Renewable Energy, 38 (2012), 169-172.

[16] Rahman I, Chen H, Reynolds D. Evidence of green signaling in green hotels. International Journal of Hospitality Management, 85 (2020), 102444.

[17] Nimri R, Patiar A, Kensbock S. A green step forward: Eliciting consumers' purchasing decisions regarding green hotel accommodation in Australia. Journal of Hospitality and Tourism Management, 33 (2017), 43-50.

[18] Yadav R, Balaji MS, Jebarajakirthy C. How psychological and contextual factors contribute to travelers' propensity to choose green hotels? International Journal of Hospitality Management, 77 (2019), 385-395.

[19] Merli R, Preziosi M, Acampora A, Ali F. Why should hotels go green? Insights from guests experience in green hotels. International Journal of Hospitality Management, 81 (2019), 169-179.

[20] Rahman I, Reynolds D. Predicting green hotel behavioral intentions using a theory of environmental commitment and sacrifice for the environment. International Journal of Hospitality Management, 52 (2016), 107116.

[21] Leroux E, Pupion PC. Factors of adoption of eco-labelling in hotel industry. Technological Forecasting and Social Change, 129 (2018), 194-209.

[22] Asadi S, OmSalameh Pourhashemi S, Nilashi M, Abdullah R, Samad S, Yadegaridehkordi E, Aljojo N, Razali NS Investigating influence of green innovation on sustainability performance: A case on Malaysian hotel industry. Journal of Cleaner Production, 258 (2020), 120860.

[23] Damigos D, Kontogianni A, Tourkolias C, Skourtos M. Behind the scenes: Why are energy efficient home appliances such a hard sell? Resources, Conservation and Recycling, 158 (2020), 104761.

[24] Banerjee A, Solomon BD. Eco-labeling for energy efficiency and sustainability: A meta-evaluation of US programs. Energy Policy, 31 (2003), 109-123.

[25] Sammer K, Wüstenhagen R. The influence of eco-labelling on consumer behaviour - Results of a discrete choice analysis for washing machines. Business Strategy and the Environment, 15 (2006), 185-199.

[26] Jaffe AB, Stavins RN. The energy-efficiency gap What does it mean? Energy Policy, 22 (1994), 804-810.

[27] Neuman WL. Social Research Methods: Qualitative and Quantitative Approaches, 7th edn, Pearson/Allyn and Bacon, Boston. 2011.

[28] Starr MA. Qualitative and mixed-methods research in economics: Surprising growth, promising future. Journal of Economic Survey, 28 (2014), 238-264.

[29] Bickman L, Rog D, Fowler F, Cosenza C. Design and Evaluation of Survey Questions. In: The SAGE Handbook of Applied Social Research Methods, SAGE Publications, Inc., 2014, 375-412.

[30] Czaja R, Blair J. Designing Surveys. Pine Forge Press; 2011.

[31] Dickson J, Fowler F, Mangione T. Improving Survey Questions: Design and Evaluation. Journal of Marketing Research, 34, 2 (1997), 296-298.

[32] Fowler FJJ. Questions to measure subjective states. In: Improving Survey Questions: Design and Evaluation, 1995, 46-77.

[33] Stopher P. Collecting, managing, and assessing data using sample surveys. Cambridge University Press; 2012.

[34] Aldrich J, Nelson F. Linear Probability, Logit, and Probit Models, SAGE Publications, Inc. 2011.

[35] Anderson JA. Regression and Ordered Categorical Variables. Journal of the Royal Statistical Society. Series B (Methodological), 46, 1 (1984), 1-30.

[36] Brant R. Assessing Proportionality in the Proportional Odds Model for Ordinal Logistic Regression. Biometrics 46, 4 (1990), 1171-1178.

[37] Greene WWH. Econometric analysis 7th Ed. Prentice Hall (Vol. 97). Pearson Education Limited, 2012.

[38] Long JS, Freese J. Regression Models for Categorical Dependent Variables Using STATA. Stata Press, 2001.

[39] Blasch J, Filippini M, Kumar N. Boundedly rational consumers, energy and investment literacy, and the display of information on household appliances. Resource and Energy Economics, 56 (2019), 39-58.

[40] Jackson J. Promoting energy efficiency investments with risk management decision tools. Energy Policy, 38 (2010), 3865-3873.

[41] Abadie LM, Ortiz RA, Galarraga I. Determinants of energy efficiency investments in the US. Energy Policy 45 (2012), 551-566.

[42] Gerarden TD, Newell RG, Stavins RN. Assessing the energy-efficiency gap. Journal of Economic Literature, $55,(2017), 1486-1525$.

[43] Gerarden T, Newell RG, Stavins RN. Deconstructing the energy efficiency gap: Conceptual frameworks and evidence. American Economic Review, 15 (2015), 183-186. 
[44] Kubiak RJ. Decision making in energy efficiency investments - A review of discount rates and their implications for policy making. Eceee Industrial Summer Study Proceedings, 2016.

[45] Bohdanowicz P, Churie-Kallhauge A, Martinac I, Rezachek D. Energy-Efficiency and Conservation in Hotels Towards Sustainable Tourism. 4th International Symposium on Asia Pacific Architecture, 2001.

[46] Styles D, Schönberger H, Martos JLG. Best environmental management practice in the tourism sector. Publications Office of the European Union, 2013.

[47] Covenant of Mayors, Technical annex to the SEAP template instructions document: The Emission Factors. Air BP Ltd 2017. 